\title{
Conhecimentos e práticas de trabalhadoras de creches universitárias relativos às infecções respiratórias agudas na infância*
}

\author{
KNOWLEDGE AND PRACTICES OF UNIVERSITY DAY CARE CENTER WORKERS RELATIVE \\ TO ACUTE RESPIRATORY INFECTIONS IN CHILDHOOD
}

\section{CONOCIMIENTOS Y PRÁCTICAS DE TRABAJADORAS DE GUARDERÍAS UNIVERSITARIAS RELATIVOS ALAS INFECCIONES RESPIRATORIAS AGUDAS EN LA INFANCIA}

\author{
Roberta Cristiane P. Alves ${ }^{1}$, Maria De Lá Ó Ramallo Veríssimo²
}

\author{
* Pesquisa de \\ Iniciação Científica, \\ desenvolvida com \\ apoio do Programa \\ Institucional de \\ Bolsas de Iniciação \\ Científica CNPq/ \\ USP. \\ 1 Enfermeira. Aluna do \\ curso de pós-gradua- \\ ção em Enfermagem \\ da Escola de Enfer- \\ magem da Universi- \\ dade de São Paulo \\ (EEUSP), nível \\ Mestrado. \\ pascarellialves@ig.com.br \\ 2 Professora Doutora \\ do Departamento de \\ Enfermagem Mater- \\ no-Infantil e Psiquiá- \\ trica da EEUSP \\ mdlorver@usp.br
}

\section{RESUMO}

Dada a elevada frequiência de infecções respiratórias agudas em creches, o objetivo deste trabalho foi identificar conhecimentos e práticas de trabalhadoras de creches relativos à prevenção, detecção precoce e manejo desses agravos. Mediante quatorze entrevistas estruturadas em duas creches universitárias da cidade de São Paulo, verificou-se que as trabalhadoras: demonstram familiaridade com diversos agravos; apontam febre e respiração ruidosa como sinais de gravidade; consideram poluição e transmissão como principais causas; referem o cuidado com o ambiente como melhor forma de controle; cuidam mantendo observação contínua da criança e intervenções de higiene e conforto e maior cuidado emocional; consideram educação e cuidado interligados no atendimento infantil, manifestando necessidade de maior preparo para cuidar; têm na prática diária a fonte de seus conhecimentos.

\section{DESCRITORES}

Conhecimentos, atitudes e práticas em saúde.

Creches.

Cuidado da criança.

Infecções respiratórias.

Bem-estar da criança.

\section{ABSTRACT}

Given the increasing frequency of acute respiratory infections in day care centers, the objective of this work was to identify knowledge and practices of day care center workers relative to the prevention, precocious detection and management of these illnesses. Through fourteen structured interviews in two university day care centers of the city of São Paulo, it was verified that the workers: demonstrate familiarity with several respiratory illnesses; indicate fever and noisy breath as danger signals; consider pollution and transmission as main causes; refer to environment care as the best form of control; keep continuous observation of the child and interventions of hygiene and comfort, and greater emotional care; consider education and care complementary in child attendance, revealing the need for better preparation for caring; have in daily activities the source of their knowledge.

\section{KEY WORDS}

Health knowledge, attitudes and practice.

Child day care centers.

Child care.

Respiratory tract infections. Child welfare.

\section{RESUMEN}

Dada la elevada frecuencia de infecciones respiratorias agudas en guarderías, el objetivo en este trabajo fue identificar conocimientos y prácticas de trabajadoras de guarderías relativos a la prevención, detección precoz y manejo de esas afecciones. Mediante catorce entrevistas estructuradas en dos guarderías universitarias de la ciudad de São Paulo, se verificó que las trabajadoras: demuestran familiaridad con las diversas afecciones; señalan fiebre y respiración ruidosa como signos de gravedad; consideran a la polución y transmisión como sus principales causas; refieren al cuidado del ambiente como la mejor forma de control; se preocupan con la observación continua del niño y con acciones de higiene, confort y cuidado emocional; consideran que la educación y el cuidado son necesarios para atender a los niños y desean mayor preparación para cuidar; tienen en la práctica diaria la fuente de sus conocimientos.

\section{DESCRIPTORES}

Conocimientos, actitudes y prácticas en salud.

Guarderías infantiles.

Cuidado del niño.

Infecciones del tracto

respiratorio.

Bienestar del niño. 


\section{INTRODUÇÃO}

Segundo a Organização Mundial de Saúde (OMS), anualmente, mais de 10 milhões de crianças morrem antes de alcançar o quinto aniversário, muitas delas no primeiro ano de vida. Sete em cada dez dessas mortes devem-se à diarréia, pneumonia, sarampo, malária ou desnutrição e, de cada quatro crianças que são levadas a um serviço ou provedor informal de assistência à saúde, três sofrem de um desses cinco agravos, ou de uma combinação dos mesmos ${ }^{(1)}$.

No Brasil, apesar da mortalidade infantil apresentar uma tendência descendente, ainda permanece elevada, com uma taxa de 29 por 1000 , sendo que as causas principais também são as acima citadas ${ }^{(2)}$. Esta cifra, contudo, obscurece enormes diferenças regionais e mesmo as iniqüidades presentes em imenso número de municípios do País, onde coexistem grupos populacionais que apresentam perfis epidemiológicos e riscos de adoecimento bastante diversos.

A magnitude com que essas doenças se apresentam, ao lado de seu impacto em termos de procura pelos serviços de saúde, determinaram que a OMS e o Fundo das Nações Unidas para a Infância (UNICEF) elaborassem uma estratégia denominada Atenção Integrada às Doenças Prevalentes da Infância $(\mathrm{AIDPI})^{(3)}$.

Dentre os agravos que compõem a AIDPI, as infecções respiratórias agudas (IRA) encontram-se entre as principais causas de morbidade e mortalidade em nosso meio. No estado de São Paulo, elas compõem o principal motivo de consultas médicas na rede pública, compreendem de 20 a $40 \%$ das internações pediátricas, e ocupam o segundo lugar na mortalidade de menores de cinco anos, sendo a pneumonia a primeira causa isolada de mortalidade entre um e cinco $\operatorname{anos}^{(4)}$.

As crianças são mais susceptíveis às infecções respiratórias devido a características anatômicas, fisiológicas e imunitárias. Em média, apresentam entre cinco e oito episódios de IRA ao ano ${ }^{(5)}$, geralmente infecções virais de vias aéreas superiores, de pouca gravidade. Entretanto, a infecção viral inicial facilita a aderência de bactérias provenientes do trato respiratório superior e sua conseqüente invasão até o sistema respiratório inferior, favorecendo a ocorrência de infecções de maior gravidade, como a pneumonia.

Em pesquisa recente acerca da mortalidade de crianças usuárias de creches no município de São Paulo, verificou-se que os óbitos por doenças respiratórias ocorreram em 36,8\% dos casos, sendo 29,6\% (66 crianças no período de 1995 a 1999) por pneumonia ${ }^{(6)}$. Além disso, nos menores de um ano, as doenças respiratórias foram responsáveis por 49,3\% dos óbitos e, nas de um a dois anos, atingiram 51\%, índices que foram diminuindo nas idades superiores.
As creches são um espaço cada vez mais presente na vida das crianças de zero a seis anos, e são diversos os estudos que apontam a freqüência à creche como um importante fator de risco para a morbidade por IRA, devido à maior exposição das crianças aos agentes infecciosos pelo confinamento e aglomeração ${ }^{(7)}$.

O controle das IRA nos países em desenvolvimento, conforme preconizado na estratégia AIDPI, depende de ações em três esferas ${ }^{(8)}$ :

- medidas preventivas: imunizações, especialmente DPT, sarampo e BCG, para prevenir alguns casos de pneumonia; controle e melhoria das condições ambientais; controle prénatal; aleitamento materno; nutrição adequada e proteção contra o resfriamento;

- atendimento dos casos: utilizando critérios de entrada padronizados e classificação precoce da gravidade da infecção; aplicação de medidas adequadas de apoio ao paciente; uso de terapia antimicrobiana adequada; definição de critérios para referência de casos a um nível superior de atenção à saúde e execução de normas adequadas de tratamento de casos dentro dos estabelecimentos do nível de referência;

- educação em saúde: a melhoria dos conhecimentos, atitudes e práticas de atenção por parte das mães e cuidadores da criança, no reconhecimento de sinais respiratórios simples e de gravidade, e na aplicação de medidas terapêuticas recomendadas.

No âmbito das creches, as práticas de cuidado à criança refletem os conhecimentos e atitudes das educadoras acerca de seu papel no atendimento infantil. Atualmente, as creches estão alocadas no setor da educação e constata-se que as trabalhadoras vêem o cuidado à criança como algo que não demanda habilidades ou conhecimentos específicos, de menor valor e subsidiário em relação à educação ${ }^{(9)}$. Sendo os cuidados a base para a sobrevivência e desenvolvimento infantil, estes, além de essenciais, são universais e, portanto, não devem ser negligenciados, desvalorizados, nem postergados ${ }^{(8)}$. Tal visão é corroborada no Referencial Curricular para a Educação Infantil que firma o cuidado como um dos componentes da proposta curricular da educação infantil ${ }^{(10)}$.

\section{Cabe ressaltar que}

é necessário e importante garantir qualidade não só no aspecto individual da educação e cuidados, mas também naqueles de ordem coletiva e epidemiológica que minimizem riscos à saúde e promovam o pleno crescimento e desenvolvimento das crianças ${ }^{(6)}$.

Assim, justifica-se este estudo considerando que nas creches atendem-se as crianças nas idades mais vulnerá- 
veis ao adoecimento, ficando seu cuidado sob responsabilidade das trabalhadoras que as assistem. Entendemos que o reconhecimento acerca das bases da atenção que é oferecida à criança nesses locais permitirá o delineamento de intervenções mais apropriadas para a melhoria do cuidado infantil. Para tanto, tivemos como objetivo identificar os conhecimentos e práticas de trabalhadoras de creche relativos aos agravos respiratórios na infância.

\section{PERCURSO METODOLÓGICO}

O estudo foi realizado em duas creches universitárias localizadas na cidade de São Paulo. A população foi constituída por doze educadoras, que são as trabalhadoras que ficam permanentemente com as crianças, realizando todas as atividades educativas e de cuidado, e duas trabalhadoras do setor de saúde das creches.

A coleta de dados deu-se mediante entrevistas estruturadas, realizadas pela pesquisadora nas creches, em local reservado, no período de setembro a dezembro de 2002, com duração média de 25 minutos cada uma. O formulário préelaborado continha uma parte de caracterização dos sujeitos, incluindo sexo, idade, grau de escolaridade, capacitação e experiência anteriores em educação infantil, e uma parte de questões sobre o tema. As questões visaram averiguar os problemas respiratórios conhecidos pelas trabalhadoras, aqueles que elas identificam como mais comuns na creche, seus sinais, sinais de gravidade, suas causas, as medidas para controlá-los e as fontes de seus conhecimentos, bem como as ações que elas realizam ou julgam ser de sua competência para melhor cuidar da criança.

O projeto foi apreciado por um Comitê de Ética e pela coordenação das creches. As participantes foram voluntárias entre o grupo total de trabalhadoras e manifestaram seu consentimento livre e esclarecido assinando termo específico.

As entrevistas foram gravadas, transcritas integralmente e submetidas à análise temática de conteúdo. Os passos seguidos para a análise temática foram: pré-análise, exploração do material e tratamento e interpretação dos resultados obtidos, determinando os temas (unidade de registro) que compuseram as duas categorias de análise.

\section{APRESENTAÇÃO E DISCUSSÃO DOS RESULTADOS}

\section{Caracterização das trabalhadoras}

As trabalhadoras concentraram-se na faixa etária de 23 a 35 anos, sendo a mediana das idades de 28 anos e meio. De todos os entrevistados, apenas um era do sexo masculino, e por isso adotamos o uso do feminino, em concordância com a maioria.
Em relação à escolaridade, $28,5 \%$ completaram o Ensino Médio, 50\% tinham Ensino Superior Incompleto e 21,5\% o Ensino Superior Completo. Além disso, 64\% tiveram alguma capacitação específica para o trabalho em educação infantil, como curso de magistério, pós-graduação, cursos oferecidos pela universidade e educação continuada na própria creche.

O tempo de trabalho das educadoras na atual creche variava entre um ano e meio e 18 anos. A maioria tinha experiências anteriores com educação infantil, em períodos que variaram de um a sete anos.

Entre as trabalhadoras de enfermagem a diferença foi mais expressiva: uma delas trabalhava há 10 anos na creche, enquanto a outra tinha iniciado há apenas 2 meses, sem ter experiências anteriores com educação infantil. Apesar de haver uma auxiliar e uma técnica de enfermagem, denominaremos a ambas "auxiliares de enfermagem", visando preservar sua identidade.

No que respeita ao conteúdo das entrevistas, como as trabalhadoras de enfermagem não se diferenciaram das educadoras em relação aos conhecimentos sobre IRA, optamos por juntá-los na apresentação dos resultados. O agrupamento dos temas identificados levou à obtenção de duas categorias, apresentadas a seguir.

\section{CATEGORIA - Conhecimentos das trabalhadoras de creches sobre problemas respiratórios na infância}

Esta categoria originou-se dos temas: problemas respiratórios conhecidos; problemas respiratórios mais comuns na creche; sinais dos problemas respiratórios; sinais de gravidade dos problemas respiratórios; causas dos problemas respiratórios.

Problemas respiratórios conhecidos - Foram citados agravos bastante diversificados, sendo os principais bronquite, rinite, gripe, pneumonia, resfriado e asma, além de dor de garganta, nariz entupido, tosse e coriza, sendo, portanto, lembradas tanto afecções do trato respiratório superior como inferior, e contendo desde nomes técnicos até sinais e sintomas, estes minoria. As experiências vividas influenciaram as respostas dadas, pois houve referências a casos de crianças da creche, e também a doenças que acometem ou acometeram os filhos ou outros familiares.

Problemas respiratórios mais comuns na creche - Diversos agravos foram reportados como comuns na creche, sendo o resfriado destacado em primeiro lugar, seguido de bronquite, gripe, pneumonia, coriza e otite. Os resfriados e as gripes foram trazidos como sendo "comuns" e "normais" na infância, por serem rotineiros, havendo uma tendência a citar doenças ou sinais mais graves como problema. No caso da pneumonia, das quatro educadoras que a citaram como um dos agravos mais comuns na creche, duas trabalham com 
crianças de 4 meses a 1 ano e meio, faixa etária na qual a morbimortalidade por pneumonia é realmente maior e expressiva.

Sinais dos problemas respiratórios - Os principais sinais de problemas respiratórios indicados foram coriza, febre, tosse, cansaço e mudança de comportamento da criança. As educadoras também referiram que a gripe seria uma intensificação dos sinais do resfriado, com quadros mais graves e mais longos. No caso da bronquite, enfatizaram cansaço, dispnéia e tosse constante. Apesar de a febre ter sido bastante lembrada, na maioria das vezes ela foi diferenciada como sendo "não tão alta" ou "uma febrinha", e também como sua presença não sendo fundamental para que um problema respiratório seja notado.

Sinais de gravidade dos problemas respiratórios - $\mathrm{O}$ sinal mais freqüentemente lembrado como de gravidade foi a febre, especificada como "mais alta, prolongada ou constante", seguida de alterações na respiração e mudança do humor da criança.

Causas dos problemas respiratórios - Foram relatadas diversas causas para os problemas respiratórios relacionadas ao ambiente, à suscetibilidade individual e ao modo de vida da criança e de sua família, como poluição, transmissão viral ou bacteriana, clima, cigarro, ambiente fechado, choque térmico, pó/poeira, vento, estresse emocional, cuidado familiar, resistência da criança, umidade e perfumes fortes.

Várias foram as afirmações contrárias às crenças populares como "vento nas costas pega pneumonia", ou que vento, chuva e frio são causas diretas; elas afirmam que a poluição, as mudanças bruscas de temperatura, a poeira, o cigarro, são causas de irritação nas vias aéreas, porém os responsáveis pelas doenças são os vírus e bactérias, que são transmitidos principalmente pelo contato, através das mãos e de ambientes fechados.

\section{CATEGORIA - A prática das trabalhadoras de creches relativa aos problemas respiratórios na infância}

Formou-se esta categoria pelos temas: ações da educadora quando a criança tem sinal de problema respiratório; habilidades consideradas importantes para o cuidado da criança com problema respiratório; ações da trabalhadora de enfermagem na creche; medidas para controlar os problemas respiratórios; dificuldades e facilidades para o cuidado da criança com problemas respiratórios.

Ações da educadora quando a criança tem sinal de problema respiratório - A ação mais reportada foi o encaminhamento da criança com qualquer sinal ou sintoma para a sala da enfermagem, para avaliação. Além disso, diante da febre alta surgem temores, o que leva as educadoras a, além de encaminhar a criança para a enfermagem, realizar medidas destinadas à redução da temperatura corporal infantil, como dar banho.

Também foi referido que o diálogo com a família da criança é fundamental, já que são os pais que decidem por procurar a ajuda de um especialista ou não. Elas mencionaram que a família deve ser orientada a levar a criança ao pediatra quando algum sinal é detectado na creche, seja pela educadora ou pela auxiliar de enfermagem, e, caso percebam algum sinal de gravidade, devem solicitar a presença dos pais para buscar a criança.

Ações que contribuem para evitar a transmissão foram lembradas por um pequeno número de trabalhadoras: estar atenta para que as crianças não troquem objetos levados à boca, manter cuidados diários de higiene, como lavagem dos brinquedos e troca dos lençóis, lavar as mãos após o uso do sanitário, antes das refeições e depois de brincar na areia, estar mais atenta às crianças com problemas respiratórios para evitar a transmissão, manter o ambiente arejado e não trocar as toalhas entre as crianças. Algumas, visando evitar a piora do quadro, recomendam realizar a limpeza do pó do local onde as crianças dormem e evitar locais com areia e pó.

Foram citados também como importantes a instilação de solução salina por via nasal e a limpeza do nariz da criança, além do estímulo à hidratação.

Ainda foram apontadas ações de acompanhamento da evolução do quadro, como observar a criança mais atentamente enquanto se alimenta e enquanto dorme, estar atenta para o apetite e anotar a alimentação da criança e observar se o comportamento da criança condiz com o normal para ela. Outras ações, voltadas a proporcionar conforto e bem-estar, foram oferecer descanso, realizar tapotagem quando julgar necessário, mantê-la com roupa adequada para a temperatura do ambiente, realizar mudança de decúbito para facilitar respiração durante o sono e respeitar seu apetite.

Além disso, foram apontados cuidados relacionados a aspectos emocionais: oferecer carinho e colo, ser receptiva com a criança e entender sua irritação, ter um olhar especial para ela, respeitar seus limites, acompanhá-la quando vai receber medicação e explicar procedimentos a serem realizados.

Outras ações são voltadas para impedir a exposição do organismo da criança ao frio, como não permitir que as crianças fiquem com roupas molhadas, desprotegidas ou descalças, estar atenta para que a criança não "pegue friagem", não expor a criança febril ao vento, não dar banho nos bebês em dias de muito frio e deixá-los bem agasalhados, dar banho cedo, não lavar os cabelos das crianças todos os dias, brincar com água em dias de sol, e logo após aquecer o 
corpo da criança. Uma das trabalhadoras relatou apenas essas práticas e apresentou conhecimentos mais restritos quanto ao tema do estudo, o que permite afirmar que sua prática é fortemente baseada no senso comum. Cabe destacar que esta era uma das mais jovens e trabalhava na creche há um ano e meio.

Habilidades consideradas importantes para o cuidado da criança com problema respiratório - As educadoras assumem como sua função o cuidado da criança, manifestando a importância de estarem atualizadas e melhor preparadas para realizarem estes cuidados. Assim, demonstraram desejo de agir com base científica, e não pelo senso comum.

Elas citam que devem ter informações verdadeiras sobre problemas respiratórios, saindo do senso comum e desfazendo os mitos em torno deles, a exemplo, conhecer as verdadeiras causas do adoecimento e modos de prevenção, bem como saber que os problemas respiratórios são comuns para as crianças da faixa etária presente na creche.

Para adquirir tais conhecimentos, afirmam que seria necessário orientação contínua pelo pessoal da saúde, mais encontros nas creches para discussões de temas relacionados à saúde, leituras individuais para aumentar os conhecimentos, além do acompanhamento do trabalho dos profissionais da saúde com as crianças.

Elas referem que devem saber agir em situações de emergência para poder ajudar ou até mesmo salvar a criança, mas naquele momento não se sentiam preparadas para isto; elas afirmaram que deveriam ter cursos de primeiros socorros, para que consigam reconhecer sinais de gravidade e saber como agir em momentos de emergência.

Ações da trabalhadora de enfermagem na creche qualquer tipo de medicação que as crianças precisem receber é de incumbência da enfermagem. Ao ser matriculada na creche, a criança e sua família passam por uma entrevista durante a qual questiona-se sobre doenças prévias, alergia a medicamentos, e se há autorização para o uso de antitérmicos em caso de febre, única droga utilizada a critério da auxiliar de enfermagem sem prescrição médica.

Quando a educadora desconfia de febre ou mal-estar da criança, é a trabalhadora de enfermagem que avalia o estado da criança, tomando as medidas cabíveis para cada caso. Este apoio é visto como tranqüilizador e aumenta a confiança das educadoras no cuidado que estão oferecendo.

Em casos de maior gravidade, quando se julga necessário que a criança seja observada mais atentamente ou mesmo levada para atendimento médico, esta trabalhadora entra em contato com os pais e os orienta a buscar a criança. Aquelas que apresentam problema respiratório, porém considerado de menor gravidade, são mantidas na creche sob sua observação direta.
Além disso, ela continuamente orienta as educadoras sobre os cuidados à criança. Para a troca dessas informações, apontam que o diálogo é fundamental. Também consideram essencial o diálogo com as famílias, para receber informações sobre a saúde da criança, avisar sobre sintomas apresentados pela criança e os procedimentos realizados.

Medidas para controlar os problemas respiratórios Foram citadas medidas de âmbito genérico, de controle do ambiente mais próximo da criança e cuidados diretos a ela. A principal medida de âmbito genérico, ou geral, considerada importante, porém difícil de ser realizada pela trabalhadora da creche, foi diminuir a poluição.

No âmbito da creche, enquanto local de permanência prolongada da criança, as trabalhadoras referiram que se deve manter o ambiente limpo e arejado/ventilado, diminuir o pó e a poeira, realizar diariamente a troca de lençóis e cobertores, lavagem de brinquedos e das mãos. No âmbito individual, foram citados: cuidados com a alimentação e uso de roupa adequada para a temperatura, e não expor as crianças à fumaça de cigarro.

Dificuldades e facilidades para o cuidado da criança com problemas respiratórios - As trabalhadoras referiram poucas dificuldades, sendo as principais a comunicação com a criança pequena e a falta de comunicação entre pais e educadores, evitar que a criança respire muito pó e brinque com água, ficar com a criança num ambiente coletivo quando precisaria de atenção individual, já que fica "mais carente" e quer o colo da mãe, e a dificuldade de impedir que a criança com problema respiratório troque brinquedos colocados à boca com os colegas. Além disso, revelaram ter dificuldades para reconhecer sinais de problemas respiratórios nas crianças pequenas e se sentirem despreparadas para ajudar em casos de emergência.

Já as auxiliares de enfermagem afirmam que não têm dificuldades, pois seguem sempre prescrições médicas e "a medicação é simples, somente por via oral".

As educadoras afirmam que o fato de poder recorrer à trabalhadora de enfermagem quando notam algo de errado com a criança é uma grande facilidade que encontram para o cuidado, pois se sentem apoiadas por alguém considerado "melhor capacitado".

Um tema presente no conteúdo das entrevistas, mas que não chegou a compor uma categoria é a Origem dos conhecimentos e informações.

As educadoras consideraram a experiência no trabalho como a melhor fonte de aprendizagem, incluindo a convivência diária com as crianças na creche, treinamentos e orientações em serviço e leituras contínuas. Citaram ainda a experiência de ver como é feito o cuidado na creche por outros profissionais, principalmente os da área da saúde. 
A formação em educação infantil foi importante na obtenção de conhecimentos segundo duas educadoras, e, para outra, os cursos paralelos. Além disso, são considerados igualmente importantes as conversas com familiares das crianças e experiências de trabalho com educação infantil em outros locais, mencionados uma vez cada.

As educadoras reportam como também essenciais para seus conhecimentos sobre problemas respiratórios suas vivências particulares, como a experiência de ser mãe, o convívio familiar, e conversas com médicos, além do próprio dia-a-dia.

As trabalhadoras de enfermagem fizeram referência aos cursos de auxiliar e técnico de enfermagem e às experiências anteriores no trabalho em hospitais.

Apesar destas creches investirem em educação continuada, as trabalhadoras afirmam que a maioria de seus conhecimentos sobre problemas respiratórios são provenientes do convívio diário com as crianças e não de cursos, já que a ênfase dada nestes é para a educação infantil e não para o cuidado à criança. Porém, consideram que educação e cuidado estão interligados no trabalho com a criança e ambos são essenciais para que o atendimento seja completo.

Além disso, muitas destacaram o fato de estarem numa creche universitária como um diferencial e um privilégio, pois afirmaram que esta preocupação com a formação contínua dos educadores não existe na maioria dos serviços.

\section{DISCUSSÃO}

O olhar sobre os resultados de forma panorâmica permite visualizar que os conhecimentos e práticas dessas trabalhadoras mostram-se apropriados, conforme explicamos a seguir.

As doenças mais citadas como conhecidas pelas trabalhadoras têm grande relevância no perfil de morbi-mortalidade da população infantil, conforme atestam estudos realizados em creches da Rede Pública Municipal de São Paulo.

Entre os dez principais diagnósticos de morbidade levantados, os três primeiros estavam relacionados ao aparelho respiratório, a saber, resfriado, bronquite e amigdalite ${ }^{(10)}$.

Ainda, o peso proporcional que as mortes por doenças respiratórias nas creches representaram em cada grupo etário foi de $49,3 \%$ nos menores de um ano, $51 \%$ nos de um ano, $27,6 \%$ nos de dois anos e $12 \%$ nos de três anos ${ }^{(6)}$.

Resfriados são freqüentes, praticamente fazendo parte do cotidiano infantil nas creches. A bronquite e a asma têm sua importância expressa nos elevados índices de morbidade e no fato de produzirem um quadro respiratório que preocu- pa e exige vários cuidados. A pneumonia é relevante, pois responde por elevados índices de hospitalização e mortalidade em nosso meio.

Certamente a essas trabalhadoras não compete fazer diagnósticos clínicos, mas seu conhecimento e compreensão acerca dos processos mórbidos podem vir a se constituir como fator de proteção da saúde infantil. Quer dizer, eles podem contribuir para melhoria dos cuidados de promoção de saúde e prevenção de doenças, reconhecimento precoce de sinais de doenças infantis e da necessidade de procura de serviços de saúde apropriados, e cuidados corretos durante e após o período de doença que favoreçam o pronto restabelecimento da criança, bem como a manutenção de seu processo saudável de crescimento e desenvolvimento.

No que diz respeito à identificação de sinais, é interessante notar que as educadoras estão atentas aos sinais específicos de problemas respiratórios, mesmo na ausência de febre, os quais são realmente significativos. Entretanto, os sinais considerados pela estratégia AIDPI como indicativos de gravidade na criança, que são a freqüência respiratória aumentada e a tiragem subcostal, não foram objetivamente referidos. É possível que a freqüência respiratória aumentada seja reconhecida pelas educadoras como "alteração na respiração", mas isto precisa ser confirmado. Ainda assim, como elas identificam outros sinais de comprometimento respiratório, como respiração ruidosa, secreção pulmonar, dificuldade para respirar e tosse, isto pode levá-las a direcionar seu olhar para o reconhecimento daqueles de maior valor preditivo de gravidade.

O reconhecimento dos sinais de gravidade, indicativos de pneumonia ou doença grave, constitui um alarme do problema e aponta para a necessidade de adoção de condutas visando sua resolução ${ }^{(12)}$. A não percepção dos sinais indicativos dos agravos respiratórios é um dos fatores que pode resultar em demora na procura ou na não procura de atenção especializada, o que aumenta a probabilidade de agravamento dos casos e, conseqüentemente, diminui a possibilidade de tratamento e recuperação da criança, explicando em parte os óbitos infantis por esta causa $^{(13)}$

As trabalhadoras demonstraram conhecer as principais causas de problemas respiratórios, utilizando referências do conhecimento científico, pois, apesar de terem citado fatores de relação direta de causa-efeito na produção do agravo (agente causal ou etiológico) bem como aqueles que, de alguma forma, favorecem ou contribuem para o adoecimento (fatores predisponentes e desencadeantes), a maioria delas sabia diferenciá-los. 
A compreensão acerca do processo de adoecimento é um aspecto sumamente importante, pois é a base para a proposição de intervenções que visam sua prevenção. Neste sentido, pudemos observar que as trabalhadoras apontam algumas medidas efetivas de controle, mas deixam de reconhecer outras que estão plenamente a seu alcance. A lavagem das mãos (de funcionários e crianças) é um dos procedimentos mais importantes para prevenir a transmissão de patógenos do trato respiratório e conseqüente disseminação da infecção, além da limpeza e desinfecção de fômites e demais objetos que entram em contato com as $\operatorname{crianças}^{(14)}$. Embora seja considerado um princípio universal de higiene, nas creches essa prática simples e eficaz é uma das mais difíceis de acontecer, quer seja na freqüência desejável, quer no modo correto de realizá-la ${ }^{(15-16)}$, o que foi confirmado em nossa investigação, uma vez que houve apenas uma referência à lavagem das mãos como meio de controle. Outros cuidados lembrados, quais sejam a lavagem nasal com solução salina e oferta mais freqüente de líquidos, são medidas fundamentais para a melhoria do padrão respiratório e manutenção da hidratação ${ }^{(14)}$.

Merece destaque a preocupação em proporcionar atenção, afeto e conforto, pois os cuidados dirigidos à pessoa e não à doença ou ao corpo demonstram uma abordagem saúde-doença mais ampla, conservando os laços afetivos e permitindo a expressão de outra dimensão do cuidado $^{(12)}$.

Pudemos constatar que os conhecimentos e práticas das participantes em questão são mais apropriados do que aqueles identificados em estudos realizados em nosso país com grupos de mães ${ }^{(12)}$, em cujos resultados identifica-se maior presença de mitos e idéias errôneas. Um dos aspectos que pode explicar que os resultados sejam mais apropriados é o nível de escolaridade das trabalhadoras, que pode ser considerado elevado se comparado ao das populações dos referidos estudos. Além disto, acreditamos que outro fator fundamental é a postura das educadoras dessas creches frente ao cuidado da criança. Ao manifestar seu desejo de terem mais conhecimentos apropriados sobre o tema em questão, as trabalhadoras trazem à tona sua visão de profissionalismo em relação aos aspectos do cuidado, o que

\section{REFERÊNCIAS}

(1) World Health Organization (WHO). Child and adolescent health and development. [on line] World Health Organization. WHO/ OMS 2000. Department of Child and Adolescent Health and Development. Avaliable from: <http://www.who.int/childadolescent-health/integr.htm $>$ (Access at 23 mai. 2002)

(2) Fundo das Nações Unidas para a Infância (UNICEF). At a glance: Brazil. Basic indicators. [online] Avaliable from: http:/ /www.unicef.org./infobycountry/brazil.html (Access at 06 abr. 2004) é fundamental para alcançar um padrão de atendimento de alta qualidade.

\section{CONSIDERAÇÕES FINAIS}

As práticas de cuidado necessárias à manutenção e recuperação da saúde infantil só podem ser implementadas pelos cuidadores à medida que estes tenham sido capacitados para isso. Mediante a educação em saúde, pode-se preparar os educadores infantis para intervenções de promoção da saúde infantil, de cuidado à criança doente e de identificação precoce dos sinais que requerem atenção em um serviço de saúde. O primeiro passo para instaurar processos educativos é o levantamento de necessidades, tendo por base conhecimentos e práticas dos cuidadores relacionados ao controle dos principais agravos à saúde infantil.

Segundo os resultados apresentados, pode-se considerar que as trabalhadoras das creches universitárias têm um bom preparo para a identificação precoce dos sinais de doenças respiratórias e de medidas para sua prevenção e controle, mas percebe-se que seu preparo poderia ainda ser melhor, oferecendo-lhes mais segurança no cuidado da criança, particularmente no que diz respeito aos sinais de gravidade, medidas rotineiras de controle de disseminação da infecção e intervenções em emergência.

Assim, fica evidente a necessidade de que a formação das educadoras contemple esse componente do cuidado, possibilitando que

\section{instituição e educadores passem a ativamente assumir seu papel de agentes de saúde, tornando-os mais aptos a diagnosticar precocemente e encaminhar mais adequada- mente as diferentes doenças que possam vir a acometer as crianças. Além disso, possibilitará que tenham tanto uma perspectiva preventiva, como competência para dar assistência de emergência, em caso de necessidade ${ }^{(17)}$.}

Para que isto seja possível, acreditamos que se faz imprescindível a aliança da Saúde e da Educação, e que particularmente a enfermagem pode e deve contribuir, ajudando a construir um referencial de atenção integral à criança e apoiando a formação dos trabalhadores da Educação Infantil ${ }^{(9,15)}$.

(3) Brasil. Ministério da Saúde. Secretaria de Políticas de Saúde. Atenção Integrada às Doenças Prevalentes da Infância; 2000. [online] Disponível em: <http://www.saude.gov.br/programas/ scriança/criança/aidpi/aidpi1.htm> (Acesso em 23 mai. 2002)

(4) Datasus. Informações de saúde. [online] Disponível em: <http:/ /tabnet.datasus.gov.br/cgi/mortinf/mibr.htm> (Acesso em 23 mai. 2002) 
(5) Lanata CF. Incidência e evolução da pneumonia em crianças a nível comunitário. In: Benguigui Y, Antuñano FJL, Schmunis G, Yunes J. Infecções respiratórias em crianças. Washington (DC): OPAS; 1998. Cap. 4, p. 63-87.

(6) Vico ESR. Estudo da mortalidade de crianças usuárias de creches no município de São Paulo. [dissertação] São Paulo: Faculdade de Saúde Pública da USP; 2001.

(7) Victora CG. Fatores de risco nas IRA baixas. In: Benguigui Y, Antuñano FJL, Schmunis G, Yunes J. Infecções respiratórias em crianças. Washington (DC): OPAS; 1998. Cap. 3, p. 43-61.

(8) Benguigui Y. Bases técnicas para a prevenção, diagnóstico, tratamento e controle das IRA no primeiro nível de atenção. In: Benguigui Y, Antuñano FJL, Schmunis G, Yunes J. Infecções respiratórias em crianças. Washington (DC): OPAS; 1998. Cap. 16, p. 335-53. (Série HCT/AIEPI-1.P).

(9) Veríssimo MLÓR, Fonseca RMGS. O cuidado da criança segundo trabalhadoras de creches. Rev Lat Am Enferm. 2003;11(1):28-35.

(10) Brasil. Ministério da Educação e do Desporto. Secretaria de Educação Fundamental. Referencial curricular nacional para a educação infantil. Brasília; 1998.

(11) Bricks LF, Leone C. Utilização de medicamentos por crianças atendidas em creches. Rev Saúde Pública. 1996;30:527-35.

(12) Sigaud CHS. Concepções e práticas maternas relacionadas à criança com pneumonia. [tese] São Paulo: Faculdade de Saúde Pública da USP; 2003.
(13) Chiesa AM, Bertolozzi MR. Estudo epidemiológico da mortalidade por infecções do aparelho respiratório em menores de 5 anos da região do Butantã, São Paulo, Brasil. In: Benguigui Y. Investigações operacionais sobre o controle das infecções respiratórias agudas. Washington (DC): OPAS; 1997. p. 1929. (Série HCT/AIEPI-2).

(14) Veríssimo MLÓR, Sigaud CHS. Assistência de enfermagem à criança com agravos respiratórios. In: Brasil. Instituto para o Desenvolvimento da Saúde. Universidade de São Paulo. Ministério da Saúde. Manual de Enfermagem/Programa Saúde da Família. Ministério da Saúde: Brasília; 2001. p. 95-8.

(15) Maranhão DG. O cuidado como elo entre a saúde e a educação: um estudo de caso no berçário de uma creche. [dissertação] São Paulo: Universidade Federal de São Paulo. Escola Paulista de Medicina; 1998.

(16) Barros AJD. Health risks among child day care centre attenders: the role of day care centre characteristics in common childhood illnesses. [thesis]. London: London School of Hygiene and Tropical Medicine; 1996.

(17) Amorim KS, Yazlle C, Rossetti-Ferreira MC. Binômios saúde-doença e cuidado-educação em ambientes coletivos de educação da criança pequena. Rev Bras Cresc Desenv Hum. 2000;10(2):3-18 